\title{
Overweight, obesity and associated factors among secondary school students in a northern city of Vietnam in $2011^{*}$
}

\author{
Huong Thi Le ${ }^{1 \# \dagger}$, Nga Thi Thu $\mathrm{Vu}^{1 \# \dagger}$, Doan Thi Thu Huyen ${ }^{1 \dagger}$, Nguyen Van Toan ${ }^{2}$ \\ ${ }^{1}$ Institute for Preventive medicine and Public Health, Hanoi Medical University, Hanoi, Vietnam; \\ \#Corresponding Author: hathuhuong@yahoo.com, vuthunga@hmu.edu.vn \\ ${ }^{2}$ Bac Giang Secondary School of Nursing No1, Hanoi, Vietnam; doanthuhuyen@hmu.edu.vn
}

Received 30 August 2012; revised 30 September 2012; accepted 6 October 2013

\begin{abstract}
Overweight and obesity is an emerging public health problem among school-aged children in Bac Giang city in the Northen part of Vietnam recently. This study aims to identify overweightobesity prevalence of secondary school children in this city and it's associated factors. The study was a nested case control in a cross-sectional study design in 1528 secondary students selected from 4 secondary schools in 2 inner communes and 2 suburban communes of Bac Giang city, Vietnam. Result: Overweight prevalence among secondary school students in Bac Giang was $6.7 \%$, the prevalence of obesity was $2.0 \%$. Overweight and obesity is more prevalence in male students, inner communes and students from family have higher income and higher food expense. Overweight and obesity was associated with higher energy intake, more fat consumption, having supplement meals and bedtime-meal, increased physical activities and increased sleep duration. Conclusion: Education campaign targeting reducing overweight and obesity should target both parents about dietary adequacy and balance and children about more physical activities.
\end{abstract}

Keywords: Overweight; Obesity; Secondary Students; Vietnam

\section{BACKGROUND}

Overweight and obesity are defined as abnormal or

\footnotetext{
*All the authors of this article declare that there is no competing of interest regarding the publication of this article.

${ }^{\dagger}$ HT Le, NTT Vu and TTH Doan were responsible for all aspects of protocol development, study coordination, data collection, data analysis and report writing.
}

excessive fat accumulation that may impair health and becoming a trendy public health problem worldwide [1-6]. In Vietnam, thanks to the improvement of socioeconomic status in recent years, there has been a changing of eating habit from a cereal based diets to diets with more meat, fish, dairy products, sugar, soft drinks, confectionary and processed food. Concurrently, emerging increase of overweight and obesity is occurring across the country among children and adolescent, especially in big cities. Studies in Vietnam have shown that overweight and obesity prevalence has been steadily upward across the country during the past decade. In the biggest city of Vietnam, the number of people overweight and obesity doubled from $21.4 \%$ and $36.8 \%$ during 3 years from 2002 to 2005. The number of obesity boys also increased three times from $6.9 \%$ in 2002 to $22.5 \%$ in 2005 [7-14]. Studies in Vietnam and elsewhere also found out that diets with high energy, more fat and protein, high level of sweet, confectionary, soft drinks consumption with low physical activities and spending more time for watching TV and playing games on computers were associated with obesity and overweight $[10,11$, 15-19]. In Bac Giang city in the Northern part of Vietnam, as according to the City Health Department, overweight and obesity has been increasing in recent years. However, full understanding of the prevalence and its associated factors are unknown; hence, scientific-based evidence for intervention formulation is absence. Therefore, we conduct this study in order to:

1) Identify the prevalence of overweight and obesity among secondary students in Bac Giang city of Vietnam in 2011.

2) Describe associated factors of overweight and obesity in secondary students in Bac Giang in 2011.

\section{STUDY POPULATION AND DESIGN}

\subsection{Study Location}

Bac Giang city, located 60 kilometers far from Hanoi 
in the north. This is the provincial city and the socioeconomic and administrative hub of Bac Giang province. The city has over 102 thousand people; live in 7 inner communes and 9 suburban communes. Each commune has one primary school, one secondary school and all children of relevant age, who have permanent living status at this commune, are all enrolled in these schools.

\subsection{Study Population}

The study population is secondary students enrolled in grade 6 to grade 9 with age ranging from 11 years old (grade 6) to 14 years old (grade 9) and a few with older age from total 16 secondary schools across the city.

\subsection{Time of Study}

From January to September of 2011.

\subsection{Design}

\subsubsection{Study Design}

This is a nested case control study in a cross sectional study. The first phase is a cross-sectional study when all study subjects were measured height and weight to identify the point prevalence of overweight and obesity. In the second phase, all subjects who were identified as overweight or obesity were paired with other none-cases subjects in the study to explore the associated factors of overweight and obesity.

\subsubsection{Sample Size and Sampling Method}

Phase 1: Multi-stage cluster was applied to recruit study's subjects. First, the list of 7 secondary schools in the inner communes and the list of other 9 schools in the suburban communes in Bac Giang city were collected from the City's Department of education. Next, 2 schools in the inner communes and 2 schools in the suburban communes were randomly selected from these lists. Then, in each school, each grade is regarded as a cluster and 3 classes from each cluster were randomly selected into the study. All students in these classes were recruited into study and were measured their height and weight.

The calculation of sample size for this phase based on the prevalence of overweight, obesity of $8.3 \%$ from a recent study in an area in Vietnam that has similar socioeconomic status as compared to Bac Giang city [11], with the level of confidence at 95\%, margin of error at $0.02 \%$ and design effect is 2 . Minimum sample size needed is 1462 students; however, in fact, 1528 students were recruited into the study.

Phase 2: All overweight, obesity students detected in the first phase will be recruited as cases and were paired with one control. The controls were students with the same age, gender and study at the same schools of cases and have normal BMI for age. Controls were selected from study subjects. Subjects in the phase 2 will be interviewed about their demographic information, eating habit, 24 h dietary, frequency of food consumption during the last week, physical activities and static activities. Parents or direct caregivers of these students were interviewed about their family's socio-economic status.

\subsubsection{Data Collection}

Student's height was measured by Microtoise height meter with the precision of 0,1 centimeter. The meter was tested and placed in a stable location and adjusted to 0 value before each measument; students were asked to take out shoes and hat and were instructed to stand straightly in the meter. Height was recorded as meter with one decimal digit. Weight was measured by electronic SECA weighter with the precision of 0, 1 kilogram. The weighter was tested and placed in a stable location; students were asked to take out all of their shoes and coats and were instructed to straightly stand in the middle of weighter. Weight was recorded as kilogram with one decimal digit. Demographic, eating behaviors and other information of students were collected by a predesigned, piloted questionnaire via face-to-face interviews. Questions regarding eating habit, 24 h-dietary and frequency of food consumption in the last week were adapted from conventional questions which are used widely in other studies in Vietnam. Socio-economic status of students' family was gathered via telephone-based interviews with their parents.

Anthrometric measurement and interviews were performed by experienced interviewers from Hanoi Medical University. Before fieldwork, all interviewers were well trained about the standard operation procedures to measure weight, height and administer interviews.

All children and their parents were carefully explained about the purpose of the study and orally accepted to participated to the study before data collection.

\subsubsection{Data Analysis}

Obesity and overweight identification. Overweight and obesity was determined using body mass index per age per gender (BMI) (a measure of weight adjusted for height, calculated as weight in kilogram divided by the square of height in meter $\left(\mathrm{kg} / \mathrm{m}^{2}\right)$ and WHO Reference 2007 for 5 - 19 years to monitor the growth of school-age children and adolescents [20].

$$
\begin{array}{ll}
\text {-Overweight: } & +1 \mathrm{SD}<\mathrm{BMI} \text { per age } \leq+2 \mathrm{SD} \\
\text {-Obesity }: & +2 \mathrm{SD}<\mathrm{BMI} \text { per age } \leq+3 \mathrm{SD}
\end{array}
$$

Nutrition need and diet's balance assessment and analysis were calculated based on the Recommended Nutrition Need for Vietnamese, published by Vietnam National Institute of Nutrition [21]. Converting from 
food intake into energy intake was performed based on the Vietnam table of food' nutritious components [22].

The data then was cleaned before entering into EPIDATA software version 2.0. We used Stata software version 11 to analyze the data. Descriptive statistic was performed. $\chi^{2}$ tests were done to test the differences of proportions of obesity and overweight among different age groups and gender. Logistic regression was performed to examine the relation between overweight, obesity and associated factors. All independent variables were first tested with univariate analysis. All important independent variables with $\mathrm{P}<0.2$ in the univariate analysis were put into multivariate logistic regression model. Multivariate logistic model was refitted, tested until the final model with the best fit was achieved.

\section{RESULT}

\subsection{Study's Subjects Description}

The response rate of participants in the study was $100 \%$ for both students and their parents. There were 1528 students, of whom 763 male students (49.9\%) and 765 female students (51.1\%) participated in the study. There was equal gender distribution across age groups. Students at 12 years old age-group took the highest percent of the total sample size (27.6\%) and $46.7 \%$ participated students were from schools situated in the inner communes of Bac Giang.

\subsection{Overweight and Obesity Prevalence}

In general, the proportion of overweight and obesity were $6.7 \%$ and $2.0 \%$ respectively. There was no significant difference of overweight and obesity across age groups. However, there was significant difference of overweight and obesity rate by gender. Both overweight and obesity rate in male students were more than 2 times significantly higher than the similar rates in female students. Students in inner communes had significantly higher proportion of overweight and obesity than those live in suburban communes (Table 1).

Overweight and obesity students had average family income significantly higher than students with normal weight do (799.2 \pm 130.1 VND vs 688.6 \pm 150.0 VND, respectively). Moreover, families of students with overweight and obesity spent significantly more money for food than families of students with normal weight do (1740.3 \pm 452.3 VND vs $1573.9 \pm 489.3$, respectively) (Table 2).

Diets analysis shows that both overweight and obesity students and students with normal weight had diets with total energy intake and energy from glucid and protid fall within the normal range but both groups had energy intake from lipid exceed the normal range (24.4\$ and $23.9 \%$ vs $18 \%$ - 20\%). Students with overweight and obesity had a significantly higher total energy intake than students with normal weight $(2342.6 \pm 468.8 \mathrm{Kcal}$ vs $2048.6 \pm 344.2 \mathrm{Kcal}$, respectively) (Table 3).

Summary of logistic analysis is presented in Table 4. Favor to eat sweet and fried food and eating practice such as frequent eating confectionary, sweet and sweeten milk were not associated with overweight and obesity. Increased total energy intake, having supplement meals, having bedtime-meal and eating fat for more than 3 times a week were associated with being overweight and obesity. In contrast, increased time for physical activities such as riding, walking, having exercise, ect. and increased sleeping duration were protective associated factors.

\section{DISCUSSION}

The prevalence of overweight, obesity among 1528 students of 4 secondary schools in Bac giang $(6.7 \%$ overweight and $2.0 \%$ obesity) was lower than the result

Table 1. Distribution of overweight, obesity by age, gender and place of residence.

\begin{tabular}{|c|c|c|}
\hline Distribution & Overweight \% (CI) & Obesity \% (CI) \\
\hline Total $(n=1528)$ & $6.7(5.5-8.0)$ & $2.0(1.3-2.7)$ \\
\hline \multicolumn{3}{|l|}{ By age group } \\
\hline 11 years old & $6.9(4.0-9.6)$ & $2.5(0.7-4.2)$ \\
\hline 12 years old & $7.8(5.2-10.4)$ & $1.2(0.1-2.2)$ \\
\hline 13 years old & $6.6(4.0-9.2)$ & $1.9(0.5-3.3)$ \\
\hline 14 years old & $5.7(2.7-7.3)$ & $2.4(0.9-3.8)$ \\
\hline \multicolumn{3}{|l|}{ By gender } \\
\hline Male & $9.6(7.5-11.7)^{* * *}$ & $2.8(1.6-3.9)^{*}$ \\
\hline Female & $3.9(2.5-5.3)$ & $1.2(0.4-1.9)$ \\
\hline \multicolumn{3}{|l|}{ By place of residence } \\
\hline Inner communes & $10.1(7.9-12.3)^{* * *}$ & $3.2(1.9-4.4)^{* * *}$ \\
\hline Suburban communes & $3.4(2.1-4.7)$ & $0.8(0.2-1.4)$ \\
\hline
\end{tabular}

Differences between proportions were tested by Fisher Exact Test. ${ }^{* * *} \mathrm{P}<0.001 ;{ }^{*} \mathrm{P}<0.05$ 
Table 2. Household economic status by overweight-obesity status.

\begin{tabular}{cccc}
\hline \multirow{2}{*}{ Household economic status } & Overweight, obesity students & Normal weight students & P (T test) \\
\cline { 2 - 4 } & $(\mathrm{M} \pm \mathrm{SD})$ & $(\mathrm{M} \pm \mathrm{SD})$ & \\
\hline Per capita average monthly food expense (million VND) & $799.2 \pm 130.1$ & $688.6 \pm 150.0$ & $\mathrm{P}<0.001$ \\
Per capita everage monthly income (million VND) & $1740.3 \pm 452.3$ & $1573.9 \pm 489.3$ & $\mathrm{P}=0.02$ \\
\hline
\end{tabular}

Table 3. Characteristic of the diets.

\begin{tabular}{cccc}
\hline Diet characteristic & \multicolumn{2}{c}{ Overweight and Obesity students Normal weight students } & Requirements of energy intake \\
\cline { 2 - 4 } & $\mathbf{( n = 8 8 )}$ & $2048.6 \pm 344.2$ & $2100-2500$ \\
Total energy intake (Kcal) & $2342.6 \pm 468.8^{* * *}$ & 18 & $12-14$ \\
Energy intake from protein/Total energy intake (\%) & 16.6 & 23.9 & $18-20$ \\
Energy intake from lipid/Total energy intake (\%) & 24.4 & 57.9 & $66-70$ \\
Energy intake from glucid/Total energy intake (\%) & 59 & 30 & $30-50$ \\
Protein from animal/Total protein (\%) & 34.9 & 35.3 & $30-50$ \\
Lipid from plant/Total lipid (\%) & 31.3 & & \\
\hline
\end{tabular}

Differences of means were performed by $\mathrm{T}$ test; ${ }^{* * *} \mathrm{P}<0.001 ;{ }^{* * *} \mathrm{P}<0.01 ;{ }^{*} \mathrm{P}<0.05$.

Table 4. Associated factors of overweight and obesity.

\begin{tabular}{|c|c|c|c|c|}
\hline \multirow{2}{*}{ Independent variables } & \multicolumn{2}{|c|}{ Univariate logistic } & \multicolumn{2}{|c|}{ Final multivariate logistic } \\
\hline & Crude OR (95\% CI) & $\mathbf{P}$ & Adjusted OR (95\% CI) & $\mathbf{P}$ \\
\hline Like eating sweet & $1(0.52-1.94)$ & 1.000 & & \\
\hline Like eating fat & $11.15(1.40-89.12)$ & 0.023 & & \\
\hline Like eating fried food & $1.05(0.58-1.89)$ & 0.880 & & \\
\hline Like drinking soft drinks & $1.73(0.95-3.15)$ & 0.071 & & \\
\hline Total energy intake by 100 calories increasement & $1.21(1.11-1.32)$ & 0.000 & $1.23(1.1-1.36)$ & 0.000 \\
\hline Having supplement meals & $1.97(1.50-5.92)$ & 0.002 & $3.87(1.51-9.94)$ & 0.005 \\
\hline Having snacks & $2.09(1.14-3.81)$ & 0.016 & & \\
\hline Having bedtime-meal & $2.11(1.10-4.04)$ & 0.025 & $2.43(1.02-5.82)$ & 0.046 \\
\hline Having fat more than 3 times/week & $2.96(1.39-6.30)$ & 0.005 & $2.61(1.01-6.78)$ & 0.048 \\
\hline Having fried food more than 3 times/week & $0.52(0.30-0.95)$ & 0.034 & & \\
\hline Having confectionary more than 3 times/week & $0.91(0.50-1.65)$ & 0.760 & & \\
\hline Having soft drinks more than 3 times/week & $1.27(0.64-2.48)$ & 0.490 & & \\
\hline Having sweeten milk more than 3 times/week & $0.77(0.41-1.45)$ & 0.420 & & \\
\hline Total time for physical activities with 10 minutes increasement & $0.94(0.90-0.99)$ & 0.009 & $(0.91-0.85-0.97)$ & 0.004 \\
\hline $\begin{array}{l}\text { Total time for inphysical activities with } 10 \text { minute increasement } \\
\text { (watching TV, playing games, reading books, ect.) }\end{array}$ & $1.053(1.02-1.09)$ & 0.006 & & \\
\hline Total time for sleeping (in hour) & $0.42(0.30-0.60)$ & 0.000 & $0.32(0.21-0.49)$ & 0.000 \\
\hline
\end{tabular}

of a similar study in Hue in 2007 [11] and lower than the rate found in other recent studies in Hanoi, Buon Ma Thuot and Ho Chi Minh city $[9,12,15,17]$. This lower prevalence in Bac Giang could be explained by higher socio-economic development and better nutrition mode in Hanoi, Ho Chi Minh city and in other regions of Vietnam.

The prevalence of overweight, obesity was higher in male students as compared with female students. This finding is similar to the finding of Le Thi Hai et al. in Hanoi in 2002, Vo Thi Dieu Hien et al. in Hue in 2007 and the findings of studies elsewhere in the region $[9,11$, 23-25].

Our study shows higher prevalence of overweight and obesity in the inner communes compared to the suburban communes, suggesting possible differences of socio-economic status, eating behaviors and physical activities.
Additionally, students with overweight and obesity had families with higher per capita income and higher money for food expense. This finding is similar to the finding of other studies [11,25].

After controlled for other factors, higher energy intake and more fat consumption were associated with overweight and obesity. Our result is similar to the result of other studies in Vietnam and elsewhere [16-18,26]. Other eating habit such as having supplement meals or bedtime-meal were also found significantly associated with overweight and obesity, suggesting that there is no need for further supplement meal and bedtime-meal for children participated in this study. In the multivariate logistic model, increased time for physical activities (riding bicycle, exercising and walking to schools) was also associated with lower risk of overweight and obesity, similar to the result of Vo Thi Dieu Hien, Duncan Scott, Hong, 
T.K et al., Pitrou Isabella and Sirikulchayanonta Chutima et al. [7,11,19,25-27]. Though it is still argued in literature about the relationship between sleep duration and overweight and obesity, we found longer sleeping time was associated with lower rate of overweight and obesity. This result is similar to the result of Tran Thi Hong Loan, Hoang Thi Minh Thu and Vo Thi Dieu Hien and studies elsewhere outside Vietnam [11,17,18,23].

However, unlike findings of other studies in Vietnam and elsewhere, frequent eating sweet, confectionary and drinking soft drinks were not found associated with overweight and obesity $[11,16,19]$, suggesting that overweight and obesity in the study population in Bac Giang is more related to dietary characteristic.

\section{CONCLUSION}

The prevalence of overweight, obesity among seconddary school students in Bac Giang city of Vietnam in 2011 was $6.7 \%$ and $2.0 \%$ respectively, lower than similar prevalence in other regions of Vietnam. The prevalence was higher in male students and students from families with higher income and higher food expense and associated with higher energy intake, more fat consumption, having supplement meals and bedtime-meal, increased time for physical activities and longer sleep duration. Parents should be educated about dietary adequacy and balance, limiting supplement meals and bedtime meal for children and children should be educated about increaseing physical activities to reduce risk of being overweight and obesity.

\section{REFERENCES}

[1] De Onis, M., Blössner, M. and Borghi, E. (2010) Global prevalence and trends of overweight and obesity among preschool children. American Journal of Clinical Nutrition, 92, 1257-1264. doi:10.3945/ajcn.2010.29786

[2] Freedman, D.S. (2011) Obesity-United States, 19882008. Morbidity and Mortality Weekly Report, 60, 73-77.

[3] Van den Hurk, K., Van Dommelen, P., Van Buuren, S. and Verkerk, H.P. (2007) Prevalence of overweight and obesity in the Netherlands in 2003 compared to 1980 and 1997. Archives of Disease in Childhood, 92, 992-995. doi:10.1136/adc.2006.115402

[4] Bonvecchio, A., Safdie, M. and Monterrubio, E.A. (2009) Overweight and obesity trends in Mexican children 2 to 18 years of age from 1988 to 2006. Salud Pública de México, 51, 586-594.

doi:10.1590/S0036-36342009001000013

[5] Nakano, T., Sei, M. and Munakata, H. (2010) Tracking overweight and obesity in Japanese children: A six years longitudinal study. The Journal of Medical Investigation, 57, 114-124. doi:10.2152/jmi.57.114 https://www.jstage.jst.go.jp/article/jmi/57/1\%2C2/57_1\% 2C2_114/_pdf
[6] Sirikulchayanonta, C., Ratanopas, W. and Temcharoen, P. (2011) Self discipline and obesity in Bangkok school children. BMC Public Health, 11, 1-8. doi:10.1186/1471-2458-11-158

http://www.biomedcentral.com/content/pdf/1471-2458-11 -158.pdf

[7] Ministry of Health (2000) National Nutrition Census in 2000. Medical Publisher, Oxford, 41-105.

[8] Nguyen, Q.D. and Nguyen, L. (2008) Obesity among school children from 9 - 11 years old and associated factors in Hanoi and Ho Chi Minh city. Journal of Food and Nutrition, 1, 20-25.

[9] Le, T.H. and Nguyen, T.L. (2003) Overweight and obesity prevalence among children from 7 to 12 years old in Hanoi in 2002. Journal of Vietnam Medical Research, 9, 25-29.

[10] Vu, H.H. and Le, T.H. (2002) Overweight and obesity and risk factors among primary school chidren in Dong Da district of Hanoi. Journal of Practical Medicine, 48, 50-55.

[11] Vo, T.D.H. and Hoang, K. (2008) Overweight and obesity among school aged children from 11 to 15 years old in some secondary schools in Hue. Journal of Practical Medicine, 1, 28-30.

[12] Hong, T.K., Dibley, M.J., Sibbritt, D., Binh, P.N.T., Trang, N.H.H.D. and Hanh, T.T.M. (2007) Overweight and obesity are rapidly emerging among adolescents in Ho Chi Minh City, Vietnam, 2002-2004. International Journal of Pediatric Obesity, 2, 194-201. doi:10.1080/17477160701520165

[13] Tuan, N.T., Tuong, P.D. and Popkin, B.M. (2008) Body mass index (BMI) dynamics in Vietnam. European Journal of Clinical Nutrition, 6, 78-86. doi:10.1038/sj.ejcn.1602675

[14] Huynh, T.T.D., Michael, J.D., Sibbritt, D.W. and Tran, T.M.H. (2005) Trends in overweight and obesity in preschool children in urban areas of Ho Chi Minh City, Vietnam, from 2002 to 2005. Public Health Nutrition, 12, 702-709.

[15] Nguyen, C.K., Cao, T.Y. and Dang, T.D. (2006) Prevalence of overweight and obesity among primary school children in inner communes of Buon Ma Thuot in 2004 and associated factors. Journal of Food and Nutrition, 2006, 22-26.

[16] Ta, T.L. (2001) Nutrition status and associated factors in children from 12 - 15 years old in two secondary schools in Hanoi. Master of Public Health Graduation Thesis, Hanoi Medical University, Hanoi, 27-45.

[17] Tran, T.H.L. (1998) Overweight and risk factors among school children from 6 - 11 years old in one inner district on Ho Chi Minh city. Master of Community Nutrition Graduation Thesis, Hanoi Medical University, Hanoi, 24-45.

[18] Hoang, T.M.T. (2003) Overweight, obesity and associated factors among children from 6 - 11 years old in Cau Giay District, Hanoi. Master of Public Health Graduation Thesis, Hanoi Medical University, Hanoi, 32-57.

[19] Duncan, S. and Duncan, E.K. (2011) Modifiable risk 
factors for overweight and obesity in children and adolescents from São Paulo, Brazil. BMC Public Health, 585, $1-9$.

[20] World Health Organization (2007) Development of a WHO growth reference for school-aged children and adolescents.

http://www.who.int/growthref/growthref_who_bull/en

[21] Ministry of Health-National Nutrition Institute (2003) Recommended nutrition need for Vietnamese people. Medical Publisher, Oxford, 10-19.

[22] Ministry of Health-National Institute of Nutrition (2000) Vietnam table of food's nutritious component. Medical Publisher, Oxford, 2000.

[23] Shi, Z., Taylor, A.W., Gill, T.K. and Martin, J. (2010) Short sleep duration and obesity among Australian children. BMC Public Health, 10, 1-6.

doi:10.1186/1471-2458-10-609
[24] Mak, K.-K., Ho, S.-Y. and Lo, W.-S. (2010) Healthrelated physical fitness and weight status in Hong Kong adolescents. BMC Public Health, 10, 1-5. doi:10.1186/1471-2458-10-88

[25] Hong, T.K., Rang, N.H.H.D., Dibley, M.J., Sibbritt, D.W., Binh, P.N.T. and Hanh, T.T.M. (2010) Factors associated with adolescent overweight/obesity in Ho Chi Minh city. International Journal of Pediatric Obesity, 5, 396-403. doi:10.3109/17477160903540735

[26] Li, Y., Zhai, F., Yang, X., Schouten, E.G., Hu, X., He, Y., Luan, D. and Ma, G. (2007) Determinants of childhood overweight and obesity in China. British Journal of Nutrition, 97, 210-215. doi:10.1017/S0007114507280559

[27] Pitrou, I. and Shojaei, T. (2010) Child overweight, associated psychopathology, and social functioning: A French school-based survey in 6- to 11-year-old children. Obesity (Silver Spring), 18, 809-817. doi:10.1038/oby.2009.278 